\title{
Analysis of the use and design of rubrics in competency assessment in engineering degrees
}

\author{
Leticia-Concepción \\ Velasco-Martínez \\ Universidad de Málaga \\ Campus de Teatinos \\ E-29071. Málaga (Spain) \\ +34- 952136637 \\ leticiav@uma.es \\ Juan-Carlos \\ Tójar-Hurtado \\ Universidad de Málaga \\ Campus de Teatinos \\ E-29071. Málaga (Spain) \\ +34- 952132543 \\ jctojar@uma.es
}

\begin{abstract}
The defining, implementation and assessment of competencies are challenges for new undergraduate and Master's degrees which must respond to current education demands. The use of rubrics in universities is considered an instrument of innovation and educational change that transforms assessment practices, both for students and educators. Furthermore, new education, focusing on the development of student competencies, implies a profound modification, not only of assessment approaches, but also of the approach towards education, instruction and teaching. Since their appearance in the university environment, the application of competencies in assessment systems has progressively grown. But, there is yet to be a solid body of knowledge providing evidence of the use of rubrics by educators as assessment instruments. In this study, rubrics have been analysed in 50 educators from the engineering departments of distinct Spanish universities. The rubrics used represent a wide variety of courses and university centres. A comparative analysis allows us to determine how these rubrics are being used (or not) to assess competencies. To do so, the type of works and tasks to which they are applied has been revealed, as well as the technical and pedagogical aspects that are considered by the educators in their design. The results and conclusions allow us to detect the educational needs of the teaching staff that hopes to use rubrics to assess competencies.
\end{abstract}

\section{CCS Concepts}

- Social and professional topics $\rightarrow$ Model curricula

\section{Keywords}

Competency-based; rubrics; engineering; higher education; teacher training 